\title{
Low Goal Ownership Predicts Drop-out from a Weight Intervention Study in Overweight Patients with Type 2 Diabetes
}

\author{
Sasja Huisman • Stan Maes • Véronique J. De Gucht • \\ Marlène Chatrou • Harm R. Haak \\ Published online: 22 December 2009 \\ (C) The Author(s) 2009. This article is published with open access at Springerlink.com
}

\begin{abstract}
Background Drop-out is a major problem in weight loss studies. Although previous attrition research has examined some predictors of drop-out, theoretically grounded research on psychological predictors of drop-out from weight interventions has been lacking.

Purpose To examine psychological predictors of drop-out from a weight reduction study in diabetes type 2 patients. Method A clinical trial was conducted with 101 overweight/ obese (body mass index $>27$ ) diabetes type 2 patients. Patients were randomly assigned to a self-regulation intervention, an active control group, and a passive control group. Psychological, somatic, socio-demographic, and lifestyle variables were examined as predictors of drop-out from baseline to 6 months follow-up.

Results Multiple logistic regression analysis indicated that low autonomous regulation or low 'goal ownership' was the best predictor of drop-out.

Conclusion It is suggested that the assessment of 'goal ownership' prior to a weight reduction intervention could identify patients who are sufficiently motivated to participate. Patients who score low on 'goal ownership' may be offered pretreatment interventions to increase their motivation.
\end{abstract}

Keywords Weight intervention · Diabetes type II ·

Self-regulation · Drop-out

S. Huisman $(\bowtie) \cdot$ S. Maes $\cdot$ V. J. De Gucht

Section of Clinical and Health Psychology, Leiden University,

Wassenaarseweg 52, PO Box 9555, 2300 RB Leiden,

The Netherlands

e-mail: shuisman@fsw.leidenuniv.nl

M. Chatrou $\cdot$ H. R. Haak

Máxima Medical Centre Eindhoven,

Eindhoven, The Netherlands

\section{Introduction}

Drop-out is a highly prevalent and serious problem in assessing the effectiveness of weight loss studies. A review on attrition from behavioral medicine treatments [1] showed that about one-third drops out from weight loss programs. Others, however, suggest that drop-out rates in weight loss studies might be as high as $80 \%[2,3]$.

Attrition research has tried to understand the reasons for dropping out from weight loss studies.

Various reasons for drop-out have been examined in the past. For many years, drop-out has been tried to link to demographic variables, such as age, social class [2], occupational factors [4], life stress, and financial factors [5]. The differences between study completers and dropouts with regard to social class, occupational factors, life stress, and financial factors might represent a more general socio-economic difference between obese patients who finish treatment and those who drop out of treatment.

Although these studies show that demographic variables have successfully been related to drop-out, Davis and Addis [1] argued that in order to improve attrition research, more attention should be paid to theoretically grounded psychological and behavioral predictors of drop-out. Their review on predictors of attrition in weight loss treatment showed that psychological and behavioral variables are the most predictive variables of drop-out from weight loss programs. Psychological variables that were found to relate to treatment drop-out were having too high treatment expectancies, low self-efficacy expectancies, low perceived success of weight loss, and low expectations of stress. Behavioral variables that were associated with study drop-out were a low number of previous diets, a high frequency of weight loss attempts, a low amount of weight loss, little exercise, and high cigarette consumption. 
The value of assessing psychological predictors of dropout was confirmed by more recent research by $[6,7]$. Grossi and colleagues [6] studied complexity of attrition in the treatment of obesity. By means of structured telephone interviews, 940 obese patients were interviewed about their reasons for dropping out from weight loss programs. Except for 'having a university degree', demographic factors were not able to distinguish study completers from study drop-outs. Practical problems, such as organizational or physical barriers, were the most mentioned reasons for drop-out. Furthermore, lack of motivation, dissatisfaction with the study (weight loss) results, lack of self-confidence, and sense of abandonment were the most important psychological reasons for drop-out as mentioned by patients.

More recently, mental disorders and personality characteristics have been examined as possible psychological predictors of drop-out. Psychiatric comorbidity, such as depression or anxiety, has been shown common in treatment seeking obese subjects $[8,9]$ and was found to relate to both attrition [10] and weight loss success $[10,11]$. De Panfilis [7] and colleagues examined personality features as possible predictors of obesity treatment drop-out, controlling for comorbid psychopathology. Results showed that study completers presented with higher scores on 'harm avoidance'. Non-completers were more likely than study completers to show psychiatric comorbidity, more specifically anxiety disorders.

Although all of the abovementioned demographic, practical, psychological, and behavioral factors have added to existing knowledge on weight loss drop-outs, the concepts are quite diverse and difficult to compare. It seems as if the call for theoretically grounded psychological predictors of weight loss drop-out has remained unanswered, so far. Therefore, the aim of this study is to add a grounded psychological theory to research on attrition in weight loss studies. The theory that has been chosen in this context is self-regulation theory. The self-regulatory predictors of dropout will be examined next to demographic and behavioral predictors of attrition.

Self-regulation (S-R) or goal theory provides a framework for differentiation between relevant motivational cognitions. S-R theory states that human actions are goaloriented, and that goal pursuit and attainment are more likely if goals are personally relevant (autonomous or own goals), if individuals feel competent to attain them (goal efficacy), receive the necessary social support (goal support), and have an adequate plan for goal attainment (goal planning) [12]. There is evidence that autonomous regulation (goal ownership) is associated with better diabetes regulation [13]. Self-efficacy has been associated with diet and exercise in diabetic patients [14]. Goal support has been associated with better diabetes regulation [15] and goal planning proved to be related to diabetes self-care and weight-related behaviors [16].

These S-R variables have thus been proven to be predictors of treatment success, but they have not been used as potential predictors of attrition. The aim of this study is therefore to examine whether S-R variables predict attrition from a weight reduction intervention in diabetes type 2 patients, next to socio-demographic (age, gender, educational level, having a partner, and hours of employment), somatic (BMI, Waist, and HbA1c), distress and lifestyle (eating habits and physical activity) variables.

\section{Methods}

A dataset of 1,316 diabetes type 2 patients from a General Dutch Hospital was screened for study inclusion. Based on inclusion criteria, 304 patients were invited for study participation by doctors, nurses, and dieticians during hospital visits. Inclusion criteria were: type 2 diabetes, body mass index (BMI) between 27 and 45, age between 21 and 70, Caucasian, and proficient in the Dutch language. Patients with co-morbidity (except for cardiovascular diseases) or under psychological or psychiatric treatment were excluded from the study. At baseline (T1), a total of 101 adult overweight (BMI 27-45) diabetes type 2 patients were included in the study. Of these 101 patients, 39 patients $(39 \%)$ dropped out from T1 to T2. Study noncompleters were defined as patients who either actively withdrew from study participation or stopped attending study meetings. These study meetings could be intervention meetings (for the patients in the intervention group) or meetings for measuring weight, waist circumference, and blood pressure control (for those in the control groups). Patients who would miss out on one or several study meetings, but then started attending again, were not defined as drop-outs. Of course, several subgroups of drop-outs could be identified, e.g., early versus late drop-outs, passive versus active drop-outs. However, the only subgroup of drop-outs that was taken into account in the analyses of this study was 'membership of the intervention or control group'.

All patients were randomly assigned to (a) a selfregulatory weight reduction intervention in addition to standard care, or (c) an active control condition consisting of a self-help diabetes lifestyle manual in addition to standard care, and (c) a passive control condition consisting of standard care for diabetes type 2 , including weight management. Data were taken at T1 and 6 months later (T2). This study was approved by the medical ethical committee of the hospital. Details of the study design have been described elsewhere [17].

Psychosocial measures were S-R cognitions [18] (goal ownership, goal efficacy, goal support, and goal planning), 
Table 1 Baseline characteristics (means and standard deviations) of study completers and noncompleters

\begin{tabular}{|c|c|c|c|c|c|c|}
\hline & \multicolumn{2}{|l|}{ Overall } & \multicolumn{2}{|c|}{ Intervention group } & \multicolumn{2}{|l|}{ Control group } \\
\hline & Completers & Noncompleters & Completers & Noncompleters & Completers & Noncompleters \\
\hline \multicolumn{7}{|l|}{ Somatic variables } \\
\hline \multirow[t]{2}{*}{ BMI $\left(\mathrm{kg} / \mathrm{m}^{2}\right)$} & $34.62(5.27)$ & $36.24(5.51)$ & $35.01(6.17)$ & $37.09(5.46)$ & $34.29(4.47)$ & $36.00(5.62)$ \\
\hline & $N=57$ & $N=31$ & $N=26$ & $N=7$ & $N=31$ & $N=24$ \\
\hline \multirow[t]{2}{*}{ Waist (cm) } & $117.42(11.52)$ & $118.98(12.15)$ & $120.17(13.63)$ & $116.43(10.86)$ & $115.03(8.88)$ & $119.70(12.61)$ \\
\hline & $N=56$ & $N=32$ & $N=26$ & $N=7$ & $N=30$ & $N=25$ \\
\hline \multirow[t]{2}{*}{ HbAlc (\%) } & $7.26(1.07)$ & $7.57(0.86)$ & $7.39(1.25)$ & $7.07(0.77)$ & $7.15(0.89)$ & $7.70(0.85)$ \\
\hline & $N=56$ & $N=30$ & $N=26$ & $N=6$ & $N=30$ & $N=24$ \\
\hline \multicolumn{7}{|l|}{ Socio-demographic variables } \\
\hline \multirow[t]{2}{*}{ Age (y) } & $59.21(7.40)$ & $56.67(10.23)$ & $60.71(6.55)$ & $57.67(8.78)$ & 57.67 (7.99) & $56.33(10.80)$ \\
\hline & $N=61$ & $N=36$ & $N=31$ & $N=9$ & $N=30$ & $N=27$ \\
\hline Gender $(\mathrm{m} / \mathrm{f})$ & $28 / 33$ & $20 / 19$ & $16 / 15$ & $6 / 4$ & $12 / 18$ & $14 / 15$ \\
\hline Having a Partner (yes/no) & $52 / 9$ & $31 / 8$ & $26 / 5$ & $7 / 3$ & $26 / 4$ & $24 / 5$ \\
\hline Educational Level (low/medium/high) & $32 / 14 / 14$ & $25 / 6 / 8$ & $13 / 8 / 9$ & $6 / 2 / 2$ & $19 / 6 / 5$ & $19 / 4 / 6$ \\
\hline \multirow[t]{2}{*}{ Hours of employment } & $8.07(15.56)^{*}$ & $14.87(18.46)$ & $6.52(14.04)$ & $12.90(17.39)$ & $9.67(17.08)$ & $15.55(19.07)$ \\
\hline & $N=61$ & $N=39$ & $N=31$ & $N=10$ & $N=30$ & $N=29$ \\
\hline \multicolumn{7}{|l|}{ Psychological variables } \\
\hline \multirow[t]{2}{*}{ Goal ownership $(1=$ low, $5=$ high $)$} & $4.06(0.64)^{* * *}$ & $2.18(0.95)$ & $4.09(0.59)^{* * *}$ & $2.61(1.11)$ & $4.02(0.70)^{* * *}$ & $2.04(0.87)$ \\
\hline & $N=59$ & $N=37$ & $N=30$ & $N=9$ & $N=29$ & $N=28$ \\
\hline \multirow[t]{2}{*}{ Goal planning ( $1=$ low, $5=$ high $)$} & $3.20(0.68)^{* *}$ & $3.70(0.90)$ & $3.25(0.60)$ & $3.68(1.10)$ & $3.16(0.76)^{*}$ & $3.71(0.83)$ \\
\hline & $N=57$ & $N=34$ & $N=31$ & $N=9$ & $N=29$ & $N=25$ \\
\hline \multirow[t]{2}{*}{ Goal efficacy $(1=$ low, $5=$ high $)$} & $3.41(0.56)$ & $3.50(0.66)$ & $3.44(0.58)$ & $3.50(0.70)$ & $3.39(0.55)$ & $3.50(0.66)$ \\
\hline & $N=60$ & $N=37$ & $N=31$ & $N=9$ & $N=29$ & $N=28$ \\
\hline \multirow[t]{2}{*}{ Goal support ( 1 =low, $5=$ high $)$} & $3.17(0,40)^{* * *}$ & $2.24(1.03)$ & $3.12(0.42)^{* *}$ & $2.41(0.85)$ & $3.22(0.39)^{* * *}$ & $2.18(1.09)$ \\
\hline & $N=54$ & $N=36$ & $N=27$ & $N=9$ & $N=27$ & $N=27$ \\
\hline \multirow[t]{2}{*}{ Diabetes self-efficacy $(1=$ low, $10=$ high $)$} & $7.56(1.08)^{*}$ & $6.65(2.32)$ & $7.44(1.09)$ & $7.56(2.21)$ & $7.66(1.06)^{*}$ & $6.42(2.33)$ \\
\hline & $N=57$ & $N=35$ & $N=28$ & $N=7$ & $N=29$ & $N=28$ \\
\hline \multirow[t]{2}{*}{ Diabetes distress (PAID; $1=$ low, $100=$ high) } & $38.07(13.14)$ & $37.00(12.54)$ & $36.79(13.11)$ & $40.00(13.31)$ & $39.36(13.28)$ & $35.88(12.34)$ \\
\hline & $N=56$ & $N=33$ & $N=28$ & $N=9$ & $N=28$ & $N=24$ \\
\hline \multicolumn{7}{|l|}{ Lifestyle variables } \\
\hline \multirow{2}{*}{$\begin{array}{l}\text { Healthy eating }(1=1 \text { day a week, } \\
7=7 \text { days a week })\end{array}$} & $5.21(1.23)$ & $4.87(1.26)$ & $5.15(1.21)$ & $5.06(1.28)$ & $5.27(1.26)$ & $4.81(1.27)$ \\
\hline & $N=57$ & $N=34$ & $N=28$ & $N=8$ & $N=29$ & $N=26$ \\
\hline \multirow{2}{*}{$\begin{array}{l}\text { Unhealthy eating ( } 1=1 \text { day a week } \\
7=7 \text { days a week) }\end{array}$} & $2.93(1.24)$ & $3.32(1.35)$ & $3.17(1.24)$ & $3.00(1.36)$ & $2.69(1.21)^{*}$ & $3.43(1.37)$ \\
\hline & $N=58$ & $N=30$ & $N=29$ & $N=8$ & $N=29$ & $N=22$ \\
\hline \multirow{2}{*}{$\begin{array}{l}1=1 \text { day a week of }>30 \text { min. } \\
\text { physical activity, } 7=7 \text { days a week) }\end{array}$} & $4.69(2.39)$ & $3.65(2.63)$ & $4.71(2.38)$ & $3.67(2.18)$ & $4.67(2.44)$ & $3.64(2.79)$ \\
\hline & $N=61$ & $N=37$ & $N=31$ & $N=9$ & $N=30$ & $N=28$ \\
\hline
\end{tabular}

$* p<.05, * * p<.01, * * * p<.001$

diabetes distress [19], and diabetes self-efficacy [20], all with good reliability and validity estimates. Bio-medical measures included weight, BMI, waist circumference, and glycemic control (HbA1c). Lifestyle measures were selfreported 'healthy eating' and exercise behavior assessed with eight items regarding the frequency of various nutrition and exercise behaviors within the past week. The variable 'healthy eating' was composed of seven items that measured the consumption of 'fat' $(2 \mathrm{x})$, 'fruit', 'vegetables', 'salt', 'red meat', and 'sweets and snacks'. Exercise behavior was assessed with the item 'On how many days in the past week did you have at least 30 minutes of moderate physical activity'? Demographic variables that were assessed were age, gender, educational level, hours of employment, and having a partner.

All statistical analyses were conducted with SPSS 16.0. For power reasons, the active and passive condition formed one control group in the analyses. Analysis of covariance 
(ANCOVAs) were conducted on the variables $\mathrm{HbAlc}$, demographic variables, diabetes self-efficacy, and diabetes distress to detect possible differences between study dropouts and completers. Multivariate analysis of covariance (MANCOVAs) was used to analyze differences between drop-outs and completers on the variables BMI and waist, the various S-R cognitions, and all of the lifestyle variables. The significant variables that were found in the (M)ANCOVA analyses were entered, together with the dichotomous variable 'allocated to intervention or control group' in a multiple logistic regression analysis to predict drop-out at T2. The first step of this multiple regression analysis controlled for possible 'gender' and/or 'age' differences.

\section{Results}

Socio-demographic, somatic, psychological, and lifestyle baseline characteristics of the 101 patients are described in Table 1. Furthermore, baseline characteristics are described for patients from the intervention and the control group, separately. From the 101 patients who participated in the study at T1, 39 patients (39\%) dropped-out at T2, more specifically this concerned ten patients from the intervention and 29 patients from the control group.

ANCOVAs (HbA1c, demographic variables, diabetes self-efficacy, and diabetes distress) and MANCOVAs (BMI and waist, S-R cognitions, and lifestyle variables; Table 1) indicated that study non-completers were employed for more hours $[t(98)=-1.98, p=.050]$ and scored lower on 'goal ownership' $[t(94)=11.53, p<.000]$, 'goal support' $[t(88)=5.99, p=.000]$ and 'diabetes self-efficacy' $[t(90)=$ 2.55, $p=.013]$. Interestingly, study non-completers scored higher on 'goal planning' [ $t(89)=-2.99, p=.004]$.

In the multiple regression analysis, patients employment, 'goal ownership', 'goal support', 'goal planning', and 'diabetes self-efficacy' were entered together with the dichotomous variable 'allocated to intervention or control group' and 'gender'. The results of this regression analysis revealed that 'goal ownership' was the only significant predictor of attrition $[\mathrm{OR}=.138,95 \% \mathrm{CI}(.038-.510, p=.003]$ (see Table 2).

\section{Discussion}

The results of this study indicate that study non-completers are best characterized on the basis of their S-R cognitions. Compared to study completers, drop-outs had lower levels of goal ownership and goal support, and surprisingly, higher levels of goal planning. In a regression analysis, low autonomous regulation or low goal ownership appeared
Table 2 Multiple logistic regression analysis of 6 month drop-out

\begin{tabular}{llll}
\hline & B & S.E. & Sig. \\
\hline Step 1. Gender & -.603 & .869 & .487 \\
Age & .046 & .056 & .408 \\
Step 2. Employment & .031 & .028 & .264 \\
Goal ownership & -2.005 & .659 & .002 \\
Goal planning & -.430 & .629 & .494 \\
Goal support & -1.080 & .871 & .215 \\
Diabetes self-efficacy & -.204 & .353 & .564 \\
\hline
\end{tabular}

the best predictor of drop-out over a 6-month time period. Patients with stronger intrinsic motivation to lose weight are thus less likely to drop out. The importance of selfregulatory cognitions has been shown in previous research. Goal ownership has been shown to be associated with lifestyle changes, medication adherence, and disease management outcomes [13, 21, 22]. Furthermore, lack of goal ownership has been associated with goal disengagement [23]. However, to the best of our knowledge, goal ownership has not yet been linked to drop-out from a (diabetes) weight loss intervention. The importance of goal support has been frequently demonstrated by its associations with both psychological and physiological outcomes in diabetes $[24,25]$ as well as other conditions [26]. In a recent metaanalysis on the effect of diabetes weight loss interventions on weight and HbAlc goal support of a partner or relative appeared an important moderator on weight loss outcomes [27]. Interventions that targeted goal support by including partners or relatives generated better weight loss results than interventions that did not include partners or relatives.

Contrary to our expectations, drop-outs reported higher levels of goal planning than study completers. This surprising finding might be interpreted in the light of phases/stages of self-regulation [12]. Study completers who were actively involved in the goal of losing weight, probably had moved beyond the phase of planning and rather focused on behaviors to actively work on goal pursuit. Drop-outs, however, might have not been able to move towards an active stage of goal pursuit and might have remained in cognitive planning activities to plan how to achieve their goal.

Contrary to previous research findings [6], our study did not detect 'self-efficacy' as a predictor of study drop-out. Differences in self-efficacy between study completers and drop-outs were found, but 6-month drop-out could not be predicted by lack of self-efficacy. The absence of this anticipated effect might be due to the specificity of the selfefficacy measure that was used in this study. Self-efficacy was assessed in the specific context of diabetes and weight loss and not in a more general, trait manner, which might be more comparable to personality characteristics. Given 
the growing awareness of the importance of personality in predicting drop-out, assessing general self-efficacy might be better able to predict drop-out than context specific self-efficacy.

In summary, self-regulatory cognitions give us more insight in the psychological barriers of completing weight loss interventions. Next to hours of employment, selfregulation cognitions could best distinguish study completers from study drop-outs. Although these outcomes are promising for attrition research in the weight loss field, this study also yielded some limitations. A first limitation concerned the fact that treatment satisfaction was assessed after completion of the group meetings in the intervention and control groups, but not at baseline. Therefore, comparison of study completers and drop-outs in treatment satisfaction was not possible. Furthermore, this study also suffered from drop-out to a great extent. The number of patients in this study therefore has been limited. Of course, drop-out was anticipated and was tried to prevent by drawing firm criteria for study inclusion, discussing realistic treatment expectations, and being flexible in study appointments. By these means, we hoped that the patients' chances of agenda conflicts would be low and that the patients with high medical comorbidity and unrealistic treatment expectations would not be included in the study. However, we speculate that the randomized controlled character of this study has increased the number of study drop-outs. Because of the randomized controlled design, it was not possible to take into account patients preferences for treatment in either intervention or control group meetings. Patients' satisfaction with the proposed treatment might therefore have decreased and chances of drop-out have increased.

With regard to the practical implications of this study, it can be suggested that assessment of goal ownership prior to a weight loss intervention could identify patients who are sufficiently motivated to take part in the intervention. Patients who score low on goal ownership may be offered pretreatment interventions, based on motivational interviewing and autonomy support to increase their personal motivation and commitment to treatment. Perceived autonomy supportiveness from diabetes care providers proved to increase patients' autonomous motivation and perceived competence, resulting in significant reductions in their $\mathrm{HbAlc}$ values over 12 months [13]. In addition, techniques to increase 'goal ownership' in overweight women with non-insulin-dependent diabetes have been proven successful in increasing session attendance and improving glycemic control [28]. Due to the small sample size of this study, it is hard to generalize the findings. More research is needed to confirm the importance of self-regulation cognitions and skills as predictors of dropout. Our findings point however at least at an important avenue, which merits to be explored further in future studies.
Open Access This article is distributed under the terms of the Creative Commons Attribution Noncommercial License which permits any noncommercial use, distribution, and reproduction in any medium, provided the original author(s) and source are credited.

\section{References}

1. Davis MJ, Addis ME. Predictors of attrition from behavioral medicine treatments. Ann Behav Med. 1999;21:339-49.

2. Bennett GA, Jones SE. Dropping out of treatment for obesity. J Psychosom Res. 1986;30:567-73.

3. Dalle Grave R, Calugi S, Molinari E, et al. Weight loss expectations in obese patients and treatment attrition: an observational multicenter study. Obesity Research. 2005;13:1961-9.

4. Kolotkin RL, Moore JM. Attrition in a behavioral weight-control program. A comparison of dropouts and completers. Int $\mathrm{J}$ Eat Disord. 1983;2:93-100.

5. Yass-Reed EM, Barry NJ, Dacey CM. Examination of pretreatment predictors of attrition in a VLCD and behavior therapy weight-loss program. Addict Behav. 1993;18:431-5.

6. Grossi E, Dalle Grave R, Mannucci E, et al. Complexity of attrition in the treatment of obesity: clues from a structured telephone interview. Int J Obes. 2006;30:1132-7.

7. De Panfilis C, Torre M, Cero S, et al. Personality and attrition from behavioral weight-loss treatment for obesity. Gen Hosp Psychiatry. 2008;30:515-20.

8. Goldsmith SJ, Anger-Friedfeld K, Beren S, et al. Psychiatric illness in patients presenting for obesity treatment. Int $\mathrm{J}$ Eat Disord. 1992;12:63-71.

9. Fitzgibbon ML, Stolley MR, Kirchenbaum DS. Obese people who seek treatment have different characteristics than those who do not seek treatment. Health Psychol. 1993;12:342-5.

10. Fabricatore AN, Wadden TA, Moore RH, et al. Predictors of attrition and weight loss success: results from a randomized controlled trial. Behav Res Ther. 2009;47:685-91.

11. Legenbauer T, de Zwaan M, Benecke A, et al. Depression and anxiety: their predictive function for weight loss in obese individuals. Obesity Facts. 2009;2:227-34.

12. Maes S, Karoly P. Self-regulation assessment and intervention in physical health and illness: a review. Appl Psychol. 2005;54: 267-99.

13. Williams GC, Freedman ZR, Deci EL. Supporting autonomy to motivate patients with diabetes for glucose control. Diabetes Care. 1998;21:1644-51.

14. Sarkar U, Fisher L, Schillinger D. Is self-efficacy associated with diabetes self-management across race/ethnicity and health literacy? Diabetes Care. 2006;29:823-9.

15. Trento M, Passera P, Tomalino M, et al. Group visits improve metabolic control in type 2 diabetes. Diabetes Care. 2001;24:9951000 .

16. Wheeler LA, Wheeler ML, Ours P, Swider C. Evaluation of computer-based diet education in persons with diabetes-mellitus and limited educational-background. Diabetes Care. 1985;8:537-44.

17. Huisman S, de Gucht VJ, Maes S, Schroevers M, Chatrou M, Haak HR. Self-regulation and weight reduction in patients with type 2 diabetes: a pilot intervention study. Patient Educ Couns. 2009;75:84-90

18. Maes S, Karoly P, de Gucht V, Ruehlman LS, Heiser W. The Self Regulation Skills Battery (SRSB) 2006; Leiden/Phoenix (AZ), Leiden University \& Arizona State University.

19. Polonsky WH, Anderson BJ, Lohrer PA, et al. Assessment of diabetes-related distress. Diabetes Care. 1995;18:754-60. 
20. van der Bijl J, van Poelgeest-Eeltink A, Shortridge-Baggett L. The psychometric properties of the diabetes management self-efficacy scale for patients with type 2 diabetes mellitus. J Adv Nurs. 1999;2:352-9.

21. Williams GC, McGregor HA, Zeldman A, Freedman ZR, Deci EL. Testing a self-determination theory process model for promoting glycemic control through diabetes self-management. Health Psychol. 2004;23:58-66.

22. Williams GC, McGregor HA, Sharp D, et al. A self-determination multiple risk intervention trial to improve smokers' health. J Gen Intern Med. 2006;21:1288-94.

23. Deci EL, Ryan RM. The 'what' and 'why' of goal pursuits: human need and the self-determination of behavior. Psychol Inq. 2000;11:227-68.

24. Pereira MG, Berg-Cross L, Almeida P, Machado JC. Impact of family environment and support on adherence, metabolic control, and quality of life in adolescents with diabetes. Int J Behav Med. 2008;15:187-93.

25. van Dam HA, van der Horst FG, Knoops L, et al. Social support in diabetes: a systematic review of controlled intervention studies. Patient Educ Couns. 2005;59:1-12.

26. Veenhof C, Van den Ende CHM, Dekker J, Köke AJA, Oostendorp RA, Bijlsma JWJ. Which patients with osteoarthritis of hip and/or knee benefit most from behavioral graded activity? Int J Behav Med. 2007;14:86-91.

27. Huisman SD, De Gucht V, Dusseldorp E, Maes S. The effect of weight-reduction interventions for persons with type 2 diabetes: a meta-analysis from a self-regulation perspective. Diabetes Educ. 2009;35:818-35.

28. Williams GC, Grow VM, Freedman ZR, Ryan RM, Deci EL. Motivational predictors of weight loss and weight-maintenance. J Pers Soc Psychol. 1996;70:115-26. 